\title{
Article \\ Comparative Study of Dynamic Stall between an Aircraft Airfoil and a Wind Turbine Airfoil in an Air-Particle Flow
}

\author{
Junjun Jin, Zhiliang Lu*(D), Tongqing Guo, Di Zhou (D) and Qiaozhong Li \\ Key Laboratory of Unsteady Aerodynamics and Flow Control, Ministry of Industry and Information Technology, \\ Nanjing University of Aeronautics and Astronautics, Yudao Street 29, Nanjing 210016, China; \\ Kenneth1988@nuaa.edu.cn (J.J.); guotq@nuaa.edu.cn (T.G.); zhoudi0417@nuaa.edu.cn (D.Z.); \\ liqiaozhong@nuaa.edu.cn (Q.L.) \\ * Correspondence: luzl@nuaa.edu.cn
}

Citation: Jin, J.; Lu, Z.; Guo, T.; Zhou, D.; Li, Q. Comparative Study of Dynamic Stall between an Aircraft Airfoil and a Wind Turbine Airfoil in an Air-Particle Flow. Appl. Sci. 2021, 11, 10920. https://doi.org/10.3390/ app112210920

Academic Editor: Giovanni Bernardini

Received: 19 October 2021

Accepted: 10 November 2021

Published: 18 November 2021

Publisher's Note: MDPI stays neutral with regard to jurisdictional claims in published maps and institutional affiliations.

Copyright: (C) 2021 by the authors. Licensee MDPI, Basel, Switzerland. This article is an open access article distributed under the terms and conditions of the Creative Commons Attribution (CC BY) license (https:// creativecommons.org/licenses/by/ $4.0 /)$.

\begin{abstract}
Dynamic stall in clean air flow has been well studied, but its exploration in air-particle (airraindrop or air-sand) flow is still lacking. The aerodynamic performance loss of aircraft (NACA0012) and wind turbine (S809) airfoils and their differences during the hysteresis loop at different pitching parameters are also poorly understood. As shown in this paper, the reduced frequency has little effect on the value of the maximum lift coefficient increment caused by particles, but a larger one can enhance the hysteresis effect and drag the angle of attack, at which the maximum increment is obtained, from the up stroke to the down stroke. The large lift coefficient increments of two airfoils and their difference also have a similar change trend with the reduced frequency. Compared to that of NACA0012 airfoil, the increments of S809 airfoil are obviously greater at three mean angles of attack, especially at $8^{\circ}$, which is the commonly used operating angle. In addition, the angle of attack, at which the maximum lift coefficient is obtained, can be significantly changed by particles in two regions: one is under the effect of deep stall, the other is under the effect of light stall at a low, reduced frequency.
\end{abstract}

Keywords: dynamic stall; gas-solid flow; airfoil; lift coefficient; reduced frequency; mean angle of attack

\section{Introduction}

Dynamic stall, caused by the continuous change of the angle of attack, has a significant effect on aerodynamic performance. It was first discovered in helicopter flow fields, more than fifty years ago [1-5]. They showed that the blade experiences vastly different loads between static and dynamic stall and indicated that the aerodynamic loading is dominated by the intense vortices shed from the vicinity of the wing leading-edge at moderate to high pitching rates. McCroskey et al. [6] further revealed that the initial vorticity of shed vortices is fed from the abrupt, unsteady separation of the turbulent boundary layer, not the laminar bubble. McAlister et al. [7] measured the surface pressure distribution, lift, drag, and pitching moment, and delineated static and dynamic characteristics of eight airfoils both in and out of stall.

Numerical modeling was employed as a new research method and the experimental equipment was also updated. Leishman and Beddoes [8] proposed a semi-empirical dynamic stall model based on the proper consideration of unsteady flow mechanisms. Tuncer et al. [9] numerically studied the unsteady flow fields around airfoils, oscillating in pitch and associated dynamic stall phenomenon. They also presented a numerical method that can be used to calculate the full viscous flow, and the results showed that the formation of the leading-edge vortices can be delayed when the reduced frequency is increased. The means of particle image velocimetry was used in the experiment by Raffel et al. [10], and the result showed the characteristic features of the dynamic stall process, the formation and development of an organized vortex structure, for increasing incidences and the subsequent 
separation. The comparison between numerical and experimental studies was conducted for four main phases of the dynamic stall process, and the result was encouraging [11]. The computational fluid dynamic successfully captured the three-dimensional dynamic stall [12]. Then, it had a good application in studying the dynamic stall of delta wings. Liu et al. $[13,14]$ implemented a finite, volume-based solver, with a rigid moving mesh and delayed detached eddy simulation (DDES), to analyze the effect of the reduced frequency (RF) on the burst point (BP), helical mode instability, pressure fluctuations, and dynamic pitching stability of a delta and double-delta wings (DW and DDW) in detail. They observed that all the pitching motions postponed the vortex breakdown, and the timeaveraged location of the BP has different changes in three sections, divided by a pair of critical RFs, which has been found in several previous experiments. They also indicated, when the upstream speed of the BP is higher than the downstream speed, the variation in the pitching moment is ahead of the AOA, which leads to dynamic instability. Conversely, when the downstream speed is higher than the upstream speed, the DDW is dynamically stable. Yi et al. [15] studied the unsteady aerodynamic characteristics of a $50^{\circ}$ sweep delta wing performing pitching oscillations at angle of attack, between $0^{\circ}$ and $60^{\circ}$, in numerical and experimental methods. They found that both the lift hysteresis and an unsteady phenomenon of leading-edge vortex evolution were significantly influenced by the pitch rate of the wing. Hu et al. [16] also indicated that the hysteresis effect of lift is magnified with the increasing reduced frequency. The virtual camber effect would dominate the flow field at a sufficiently high reduced frequency, which mitigates the impact of wing geometry on the lift characteristics.

Except on aircrafts, the study of dynamic stall on horizontal axis wind turbines (HAWTs) was also conducted. Butterfield et al. [17] analyzed how dynamic stall varies throughout the blade span of a $10 \mathrm{M} \mathrm{HAWT}$, during yawed and unyawed operating conditions. Shipley et al. [18] provided a statistical representation of dynamic stall occurrence on a downwind HAWT, after analyzing the surface pressure data from the National Renewable Energy Laboratory (NREL). They developed two hypotheses to explain the discrepancy at $30 \%$ span and estimated the frequency of dynamic stall on upwind wind turbines. Ramsay et al. [19] conducted a series of steady state and unsteady wind tunnel tests for the S809 airfoil. Ekaterinaris and Platzer [20] addressed some challenging numerical aspects of dynamic stall, such as the prediction of flow reattachment and three-dimensional (3D) effects. Larsen et al. [21] developed a model for aerodynamic lift of wind turbine profiles, based on a backbone curve, in the form of the static lift, as a function of the angle of attack. It combines memory delay effects under attached flow with reduced lift, due to flow separation under dynamic stall conditions. A new prediction technology for dynamic stall, based on the Leishman-Beddoes model, was given by Sheng et al. [22]. In a recent experiment by Pruski and Bowersox [23], they observed the formation and complex evolution of the leading-edge vortex and modified the classical dynamic-stall conceptual model, which is specifically related to the dynamics of the leading-edge vortex. Liu et al. [24] improved the Beddoes-Leishman (B-L) model to account for the characteristics of wind turbine airfoils which have a larger thickness-to-chord ratio compared to aviation airfoils and operate at lower Mach numbers. A series of validations on S809 airfoil are performed to illustrate its advantage.

Martinat et al. $[25,26]$ recommended that the transition model is necessary for accurately predicting dynamic stall at the lower Reynolds number of $10^{5}$. Both $2 \mathrm{D}$ and 3D calculations were carried out, and the results with the SST $k-\omega$ model were closer to the experimental data during the up stroke. The 2D RANS simulation is more excellent in capturing significant parts of the coherent large dynamics. Guntur et al. [27] adopted the DDES SST $k-\omega$ model, which is combined with the laminar/turbulent transition modeled (the $\gamma-\operatorname{Re}_{\theta}$ model), to present the combined effects of dynamic stall and rotational augmentation in the inboard parts of wind turbine blades. A further investigation was implemented by Zhu et al. [28]; they employed the transition SST model and found that these combined effects can dramatically reduce the sectional lift, drag hysteresis by almost 
$60 \%$ and $80 \%$, and delay the onset of stall, compared to either the rotational augmentation and dynamic stall. Li et al. [29,30] employed the plasma flow to optimize the performance of airfoil dynamic stall in the experiment and numerical calculation, respectively. The large eddy simulation (LES) was well applied in their research. Their results both showed that the strength of the dynamic separation vortex decreases and average aerodynamic force increases under the plasma flow loading. Zhu et al. [31,32] investigated the action of vortex generators under dynamic stall and concluded that the transition SST $k-\omega$ model is more suitable for the simulation of dynamic stall, and the vortex generators can elevate the maximum lift coefficient by almost $40 \%$. They also presented comparative analysis of dynamic stall among the 2D airfoil, 3D non-rotating blade, and 3D rotating blade undergoing sinusoidal pitch oscillations. The flow mechanism of three-dimensional dynamic stall is further revealed. In summary, the transition SST $k-\omega$ model is crucial to accurately predict the dynamic stall in a highly efficient simulation.

As shown above, the research of dynamic stall on aircrafts and wind turbines in a clean air flow is without interruption since it was discovered. However, the associated exploration in a gas-solid flow is seriously lacking because of the small effect on the aerodynamic performance of an aircraft. He [33] studied the effect of sand particles on the dynamic stall characteristics of NACA0012 airfoil at different particle diameters and concentrations. She preliminarily revealed the changes of airfoil aerodynamic performance, flow structure, and movement characteristics of particles in a gas-solid flow. In her study, it is found that the effect of particles on dynamic stall of NACA 0012 airfoil is small and negligible at a common particle concentration. Guo et al. [34] compared the effect of particles on aerodynamic performance of aircraft wind turbine airfoils. They found when the NACA0012 airfoil runs in a steady air-particle flow, with a particle mass concentration of $1 \%$, lift coefficient penalties are about $0.2 \%$ and $1 \%$ at the operating angles of attack of the aircraft and the wind turbine, respectively. However, for S809 airfoil, the relative increment of $5.74 \%$ is obtained at the operating angle of attack. Therefore, it is significant to study the aerodynamic performance loss of the wind turbine airfoil by particles and the exploration under the effect of dynamic stall is also urgent to be presented. Furthermore, He [33] only focused on the effect of particle characteristics on the hysteresis loop. This paper considers the effect of pitching parameters on hysteresis loops of aircraft and wind turbine airfoils in a gas-solid flow and analyses their difference in different cases.

\section{Computational Model}

\subsection{Numerical Method}

The 2D, incompressible URANS equations are solved by ANSYS/FLUENT, for simulating the unsteady flow around a pitching airfoil. The governing equations are written as:

$$
\begin{gathered}
\frac{\partial \rho}{\partial t}+\frac{\partial\left(\rho u_{i}\right)}{\partial x_{i}}=0 \\
\frac{\partial\left(\rho u_{i}\right)}{\partial t}+\rho u_{j} \frac{\partial u_{i}}{\partial x_{i}}=-\frac{\partial p}{\partial x_{i}}+\rho \nu \nabla^{2} u_{i}+F_{P, i}
\end{gathered}
$$

where $x_{i}$ stands for a coordinate direction, $u_{i}$ denotes a component of fluid velocity vector, $\rho, p$, and $v$ are the fluid density, pressure, and kinematic viscosity coefficient, respectively, and $F_{P, i}$ refers to the momentum source term, accounting for the particle effect on the fluid phase.

According to the conclusion by Ekaterinaris and Platzer [20], considering the transition from laminar to turbulent flow is crucial to accurately predict dynamic stall. Therefore, the transition SST model (also known as the $\gamma-\operatorname{Re}_{\theta}$ model) is adopted for turbulence modeling, which couples the SST $k-\omega$ eddy viscosity model [35] and two other transport equations [36].

$$
\frac{\partial k}{\partial t}+\frac{\partial}{\partial x_{j}}\left(u_{j} k\right)=\frac{1}{\rho} \frac{\partial}{\partial x_{j}}\left(\Gamma_{k} \frac{\partial k}{\partial x_{j}}\right)+\frac{G_{k}-Y_{k}}{\rho}
$$




$$
\begin{gathered}
\frac{\partial \omega}{\partial t}+\frac{\partial}{\partial x_{j}}\left(u_{j} \omega\right)=\frac{1}{\rho} \frac{\partial}{\partial x_{j}}\left(\Gamma_{\omega} \frac{\partial \omega}{\partial x_{j}}\right)+\frac{G_{\omega}-Y_{k}+D_{\omega}}{\rho} \\
\frac{\partial \gamma}{\partial t}+\frac{\partial\left(u_{j} \gamma\right)}{\partial x_{j}}=\frac{P_{\gamma 1}-E_{\gamma 1}+P_{\gamma 2}-E_{\gamma 2}}{\rho}+\frac{1}{\rho} \frac{\partial}{\partial x_{j}}\left[\left(\mu+\frac{\mu_{t}}{\sigma_{\gamma}}\right) \frac{\partial \gamma}{\partial x_{j}}\right] \\
\frac{\partial \operatorname{Re}_{\theta t}}{\partial t}+\frac{\partial\left(u_{j} \operatorname{Re}_{\theta t}\right)}{\partial x_{j}}=\frac{P_{\theta t}}{\rho}+\frac{1}{\rho} \frac{\partial}{\partial x_{j}}\left[\sigma_{\theta t}\left(\mu+\mu_{t}\right) \frac{\partial \operatorname{Re}_{\theta t}}{\partial x_{j}}\right]
\end{gathered}
$$

The further description of the variables in these four equations can be found in the citied papers. This model has been proven to be reliable in predicting dynamic stall of airfoils $[28,31,32,37]$.

For the simulation of unsteady incompressible flows, the PISO algorithm [38] is suitable, which has been proven by a series of research $[28,31,32,37]$. In the spatial discretization, the least square cell-based and second-order are employed to compute the gradient and pressure equation. The other convection-diffusion equations are solved with a third-order MUSCL scheme. A second-order implicit scheme is used for time-dependent solution formulation.

The discrete phase model (DPM) is employed to calculate the particle motion. A two-way coupled scheme is adopted, and particles are assumed to be non-interacting, nondeforming, and non-evaporating spheres. Then, the particle trajectories can be solved by:

$$
\begin{gathered}
\frac{d v_{p}}{d t}=\beta\left(v_{a}-v_{p}\right)+g\left(\frac{\rho_{p}-\rho_{a}}{\rho_{p}}\right) \\
\frac{d x_{p}}{d t}=v_{p}
\end{gathered}
$$

where the subscripts $p$ and $a$ denotes the particle and air, $v$ is the velocity vector, $g$ is the acceleration of gravity, $x_{p}$ is the particle position, and the term $\beta\left(v_{a}-v_{p}\right)$ is the drag of per unit particle mass, with $\beta$ being calculated from:

$$
\beta=\frac{3 \rho C_{D, p}\left|v_{a}-v_{p}\right|}{4 \rho_{p} D_{p}}
$$

where $D_{p}$ is the particle diameter and $C_{D, p}$ is the particle drag coefficient, estimated by using the spherical drag law of Morsi and Alexander [39].

\subsection{Numerical Validation}

Two airfoils are considered. One is the $\mathrm{S} 809$ airfoil, which has the maximum relative thickness of $21 \%$, and the maximum relative camber (of $0.95 \%$ ) is specifically used in the NREL Phase VI wind turbine. The other is the NACA 0012 airfoil. Figure 1a shows an O-type computational domain with a diameter 50 times as long as the airfoil chord length (c). It contains a smaller circular domain surrounding the airfoil, as shown in Figure 1b, which has a $3 c$ diameter and can rotate around the quarter chord position. After a grid independence study, they, respectively, have the sizes of $553 \times 78$ and $553 \times 199$, with a total mesh number of 153,181, which is much larger than that given by Zhu et al. [37]. At least 25 grid cells, in vertical the direction, are used to resolve the boundary layer, and the first cell height is set to make the dimensionless normal distance from wall less than 1 .

The pitching motion of the airfoil is defined by:

$$
\alpha(t)=\alpha_{m}+\alpha_{A} \sin (2 \pi f t)
$$


where $\alpha_{m}, \alpha_{A}$, and $f$ are the mean angle of attack, the amplitude, and the frequency of oscillation, respectively. The reduced frequency is defined as:

$$
\omega_{\text {red }}=\frac{\pi f c}{V_{\infty}}
$$

where $V_{\infty}$ denotes the free-stream velocity.

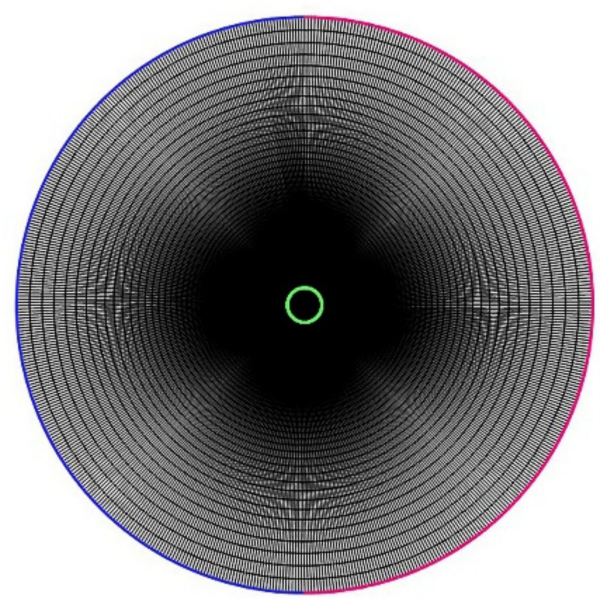

(a)

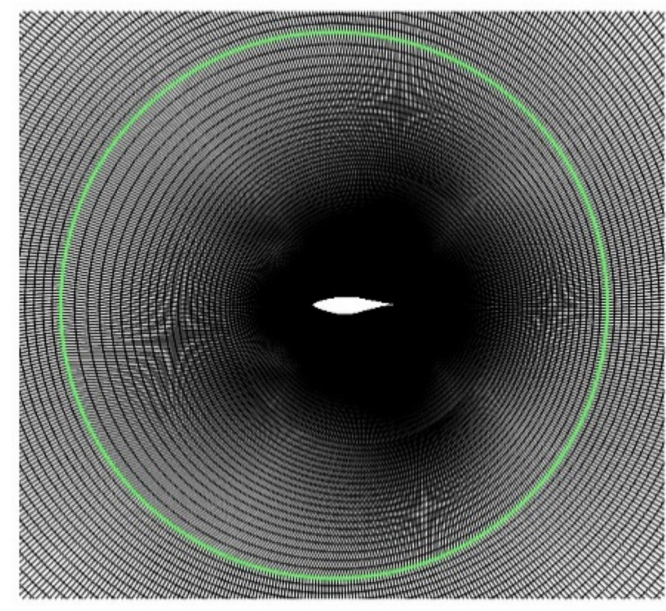

(b)

Figure 1. Computational field and mesh: (a) the blue and red semicircle edges are the velocity-inlet and pressure-outlet boundaries, respectively; (b) the green circle edge is the interface between the stationary domain and the rotating domain.

A turbulence intensity of $0.1 \%$, which is frequently used in the low turbulence windtunnel experiment $[40,41]$, is adopted at the inlet and outlet boundary, and the no-slip condition is used on the airfoil surfaces. The physical time step size is set as $5 \times 10^{-4} \mathrm{~s}$. The correlation pitching parameters are listed in Table 1. Figure 2a shows lift coefficient hysteresis loops of S809 airfoil by numerical and experimental [19] methods in a clean air flow. It was found that the iteration number has great effect on the result, and a number of 80 is an appropriate choice to achieve the balance between accuracy and efficiency. The moment coefficient loop with an iteration number of 80 is shown in Figure 2b, and the good agreement with the experimental result is a further support for the choice.

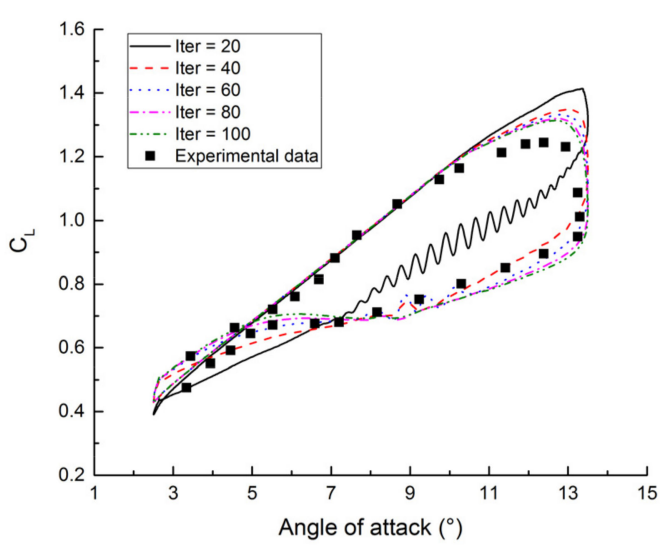

(a)

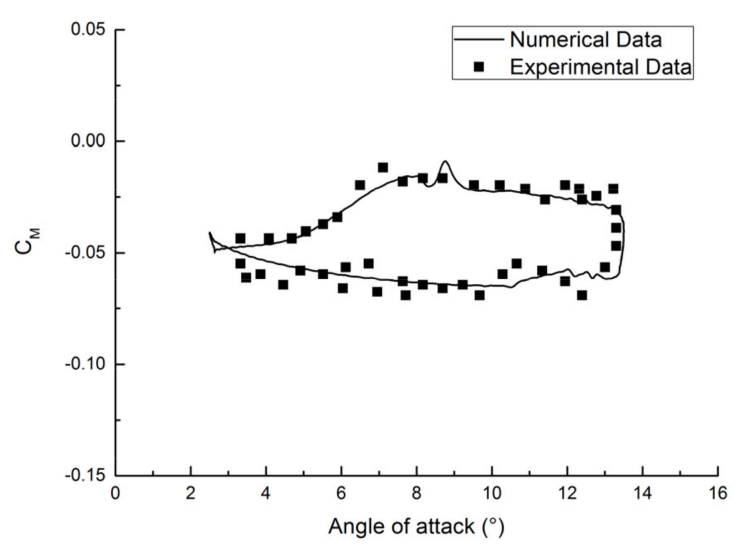

(b)

Figure 2. Numerical and experimental data of time-varying aerodynamic coefficients: (a) lift coefficient loops; (b) moment coefficient loops. 
Table 1. Correlation pitching parameters of the validation.

\begin{tabular}{ccccc}
\hline $\boldsymbol{R e} \times \mathbf{1 0}^{\mathbf{6}}$ & $\boldsymbol{\alpha}_{\mathrm{m}}\left(^{\circ}\right)$ & $\boldsymbol{\alpha}_{\mathrm{A}}\left(^{\circ}\right)$ & $f(\mathbf{H z})$ & $\omega_{\text {red }}$ \\
\hline 1.01 & 8 & 5.5 & 1.85 & 0.077 \\
\hline
\end{tabular}

Figure 3 displays the streamwise velocity distributions of air in the wake of a circular cylinder at three Stokes numbers of $0.98,6.5$, and 19.7. In these three cases, comparisons between numerical results and those from a gas-solid experiment [42] are good, indicating the used DPM is reliable.

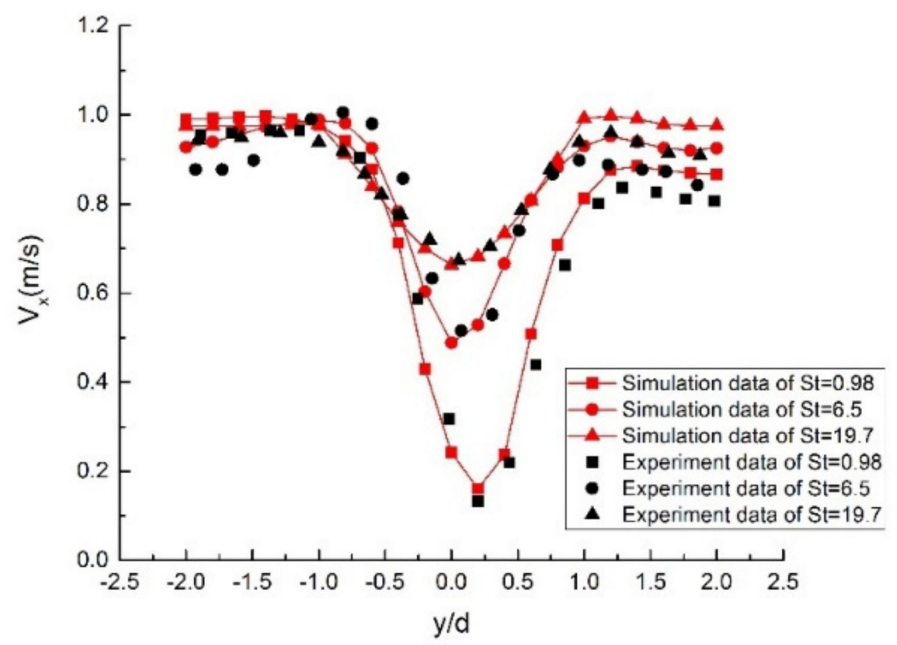

Figure 3. The streamwise velocity distributions of air in the wake of a circular cylinder at three Stokes numbers.

\section{Results}

\subsection{Hysteresis Loops at Different Reduced Frequencies}

In this section, hysteresis loops of the lift coefficient and their difference at three reduced frequencies, listed in Table 2, in clean air and air-particle flows are discussed. All cases are computed on a 12-core workstation with a CPU frequency of $3.4 \mathrm{GHz}$.

Table 2. The parameters of three pitching cases and their mean computational efficiencies.

\begin{tabular}{|c|c|c|c|c|c|c|c|}
\hline $\begin{array}{c}\text { Case } \\
\text { Number }\end{array}$ & $\begin{array}{c}\text { Stokes } \\
\text { Number (St) }\end{array}$ & $\operatorname{Re} \times 10^{6}$ & $\alpha_{m}\left(^{\circ}\right)$ & $\alpha_{A}\left({ }^{\circ}\right)$ & $f(\mathrm{~Hz})$ & $\omega_{\text {red }}$ & $\begin{array}{c}\text { Mean Computation Time of a } \\
\text { Pitching Period in the } \\
\text { Air-Particle Flow (hour) }\end{array}$ \\
\hline Case 1 & \multirow{3}{*}{0.053} & \multirow{3}{*}{1.01} & \multirow{3}{*}{8} & \multirow{3}{*}{5.5} & 0.37 & 0.0154 & 60 \\
\hline Case 2 & & & & & 1.85 & 0.0770 & 15 \\
\hline Case 3 & & & & & 3.33 & 0.1386 & 8 \\
\hline
\end{tabular}

Figure 4 shows the hysteresis loops of two airfoils, in four cases, in a clean air flow. For NACA0012 airfoil, the lift coefficient has a linear change with the angle of attack in the steady case, and the values during the up stroke are approximate to those during the down stroke in every pitching case. Three loops also have little difference, except for the inclined angle. However, for $\mathrm{S} 809$ airfoil, according to the analysis of the steady case by Guo et al. [34], the lift coefficient stops linearly increasing and decreases slightly near the angle of attack of $8^{\circ}$, due to the forward movement of the boundary-layer separation point from the trailing edge, which is called the light stall. During the following stroke, the lift coefficient increases again and drops into deep stall at an angle greater than $16^{\circ}$. In three pitching cases, the reduced frequency has large effect on the hysteresis loop. The lift 
coefficients during the up stroke are greatly different from those during the down stroke, which will be discussed as follows, and the mechanisms are also revealed.

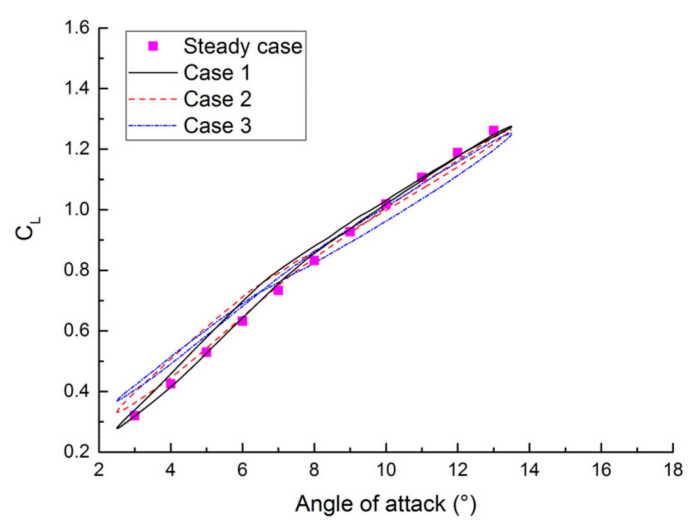

(a)

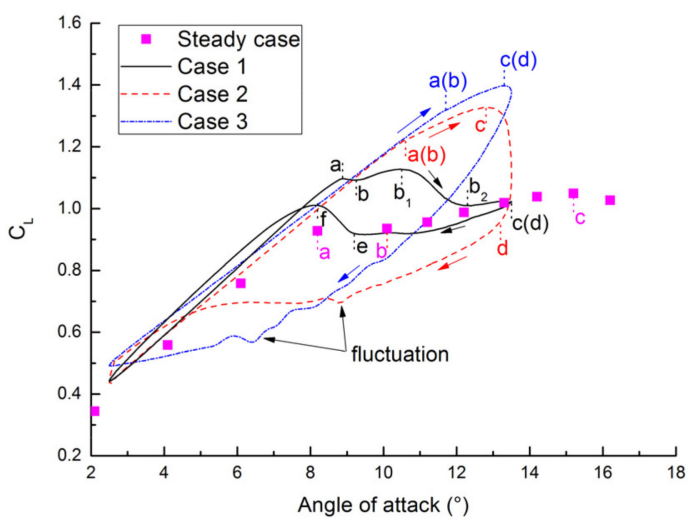

(b)

Figure 4. Lift coefficient hysteresis loops of two airfoils in four cases in a clean air flow: (a) NACA0012 airfoil; (b) S809 airfoil.

In the low reduced frequency case (Case 1), the loop during the up stroke has similar trend with the steady results. As shown in the Figure $4 \mathrm{~b}$, the loops are divided into several segments for comparison purposes. Due to the hysteresis effect, a larger range of the linear segment is obtained, and the segment ab has a smaller range than that of the steady case. In segment $b_{1} b_{1}$, the lift coefficient increases again because of the higher suction peak, which is shown in Figure 5. With the angle of attack increasing, the leading-edge vortex and suction peak barely change, the boundary-layer separation point goes forward rapidly. At the same time, the continuously decreasing pitching speed also cause the lift coefficient to approach the value of the steady case. They both lead to the decrease of the lift coefficient in segment $b_{1} b_{2}$. Then, a similar change to the steady case is presented, until the angle of attack reaches to its maximum value. In the segment de, the lift coefficient keeps close to the steady result because of the slow pitching speed. Notably, the light stall is still effective in this segment. With the further decrease of the angle of attack in segment ef, the airfoil no longer suffers the effect of light stall, the boundary-layer reattaches, and the lift coefficient increases. Finally, the linear change reappears at angles of attack smaller than $8.1^{\circ}$, and the lift coefficients are larger than those during the up stroke.

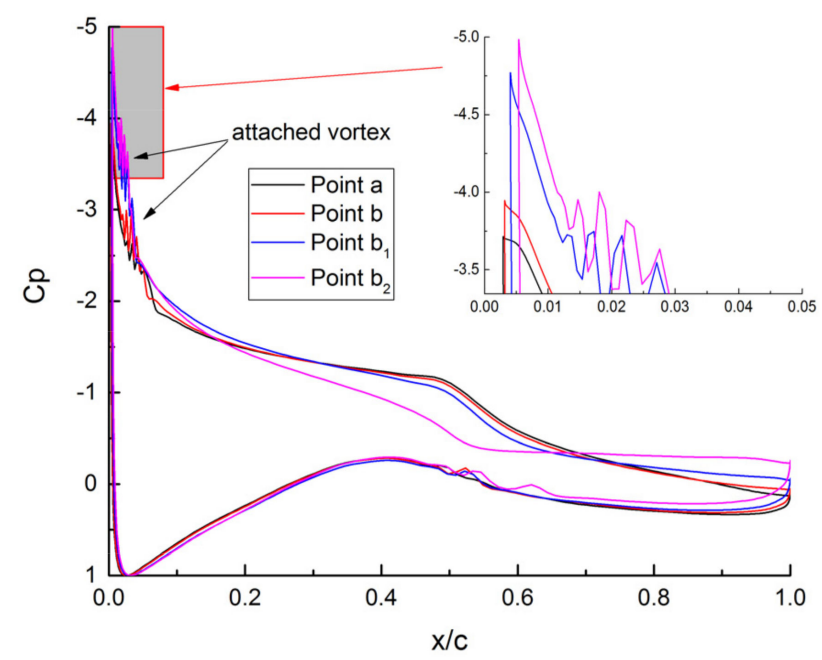

Figure 5. Pressure coefficients of four points for case 1.

In the moderate reduced frequency case (Case 2), the linear segment ends up at a larger angle of attack and the segment ab disappears, due to the greater pitching speed. Under 
the effect of light stall, the lift coefficient in segment ac increases at a smaller speed. Then, in the segment $\mathrm{cd}$, the leading-edge vortex sheds, and the lift coefficient drops sharply, which is defined as deep stall (or full stall). In the following segment, the lift coefficient slowly decreases to the initial value of the up stroke.

In the high reduced frequency case (Case 3), the range of linear segment further increases and the segment ac becomes smaller. There are only two segments during the whole up stroke, and the deep stall also disappears, due to the high pitching speed. That is because the virtual camber effect, which was discussed by Hu et al. [16], starts to dominate the flow field. In addition, the fluctuations in case 2 and 3 are caused by the small number of the inner iteration per step, which is described in Figure 2a. In the following discussion, the fluctuation will become larger, due to the hysteresis effect, especially in the loop of the relative increment between clean air and air-particle cases. Therefore, the mean value is more accurate.

Next, the cases in the air-particle flow are added to the comparison. For the three cases above, increment loops of the lift coefficient of two airfoils, caused by particles, are presented. Figures 6 and 7 display the loops for Case 1 at different particle mass concentrations and the relative increments between concentrations of $0 \%$ and $1 \%$, respectively. For NACA0012 airfoil, particles have little effect on the shape of the lift coefficient loop but a decrease for its inclined angle. The flat loop of the relative increment indicates the small loss in aerodynamic performance throughout and its little difference between up and down strokes. The peak value of $-2.016 \%$ is obtained at the maximum angle of attack. For S809 airfoil, the relative increment loop is also divided into several segments, as well as the discussion in Figure $4 \mathrm{~b}$. During the up stroke, particles make the linear segment end up at a larger angle of attack, which increases with the particle concentration. The segment $\mathrm{ab}$ is obtained at larger angles of attack; its relative increment decreases first and then increases. In these two segments, the relative increments are both small enough to be out of consideration. Due to the large difference between increments at Point $b$ and Point $b_{1}$ by particles, the change of segment $b b_{1}$ strongly depends on the particle concentration. It means that the angle of attack, at which the maximum lift coefficient is obtained, has two possibilities. As shown in Figure $6 b$, the lift coefficient of segment $b_{1} b_{1}$ increases with the angle of attack at the particle concentration of $0 \%$, and a decrease is presented at the concentration of $2 \%$. The concentration of $1 \%$ is the critical value. Then, the maximum lift coefficients at concentrations of $0 \%$ and $2 \%$ are 1.127 and 1.087 , which are obtained at angles of attack of $10.5^{\circ}$ (Point $b_{1}$ ) and $9.25^{\circ}$ (Point $b$ ), respectively. In this segment, the relative increment rapidly increases. In addition, particles make the Point $b_{1}$ move to a smaller angle of attack and the larger the concentration, the larger the movement distance and smaller the range of segment $b_{1}$. In the following three segments, the lift coefficient in the air-particle flow is approximately parallel to that in the clean air flow. The relative increment continues to increase, and the maximum value of $-6.55 \%$ is obtained at the angle of attack of $11.3^{\circ}$ in segment $b_{1} b_{2}$. In whole segment $b_{2} c$ and the first half of segment de, the relative increment is around $3 \%$, and when the angle of attack decreases to $10^{\circ}$, it increases to a peak value of $-4.5 \%$. Then, the increment rapidly decreases, until the positive value is obtained. Compared to that in the clean air flow, the Point E appears at a larger angle of attack in the air-particle flow. It means that particles can advance the reattach of the boundary layer. The range of segment ef increases with the particle concentration because the influence of particles at Point e is larger than that at Point $f$. Due to the hysteresis effect, two loops ( $\mathrm{m}=0 \%$ and $1 \%$ ) intersect in this segment and a positive peak relative increment of $2.16 \%$ is obtained at the angle of $9.06^{\circ}$. Then, it decreases until the negative value is obtained again. Finally, in the linear segment, the relative increment changes in a negligible range, although it is larger than that during the up stroke. 


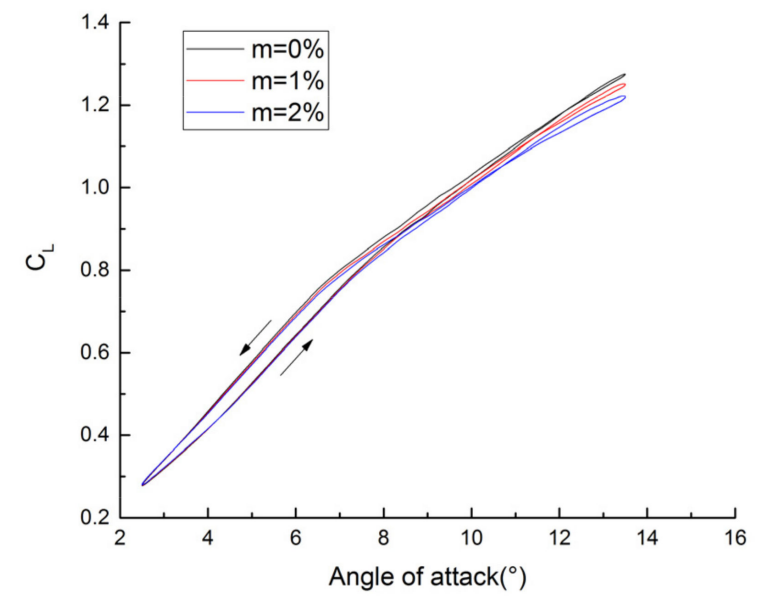

(a)

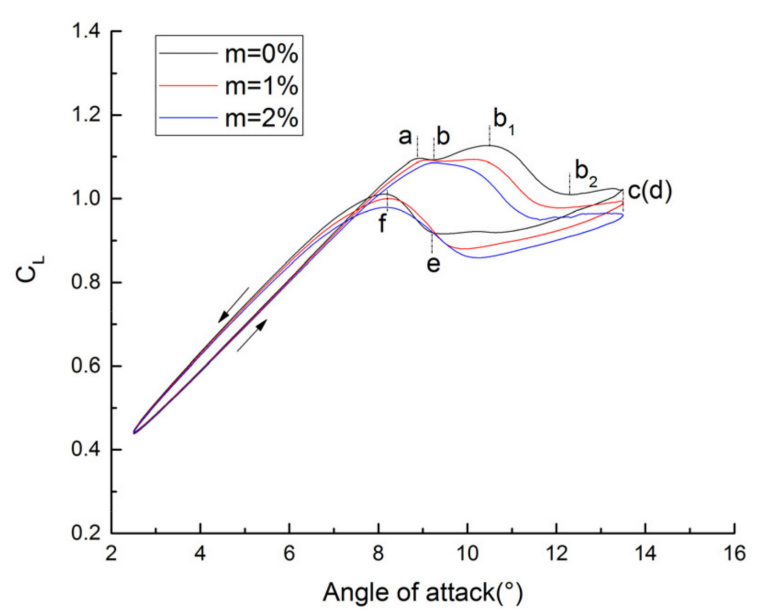

(b)

Figure 6. Lift coefficient hysteresis loops of two airfoils for Case 1: (a) NACA0012 airfoil; (b) S809 airfoil.

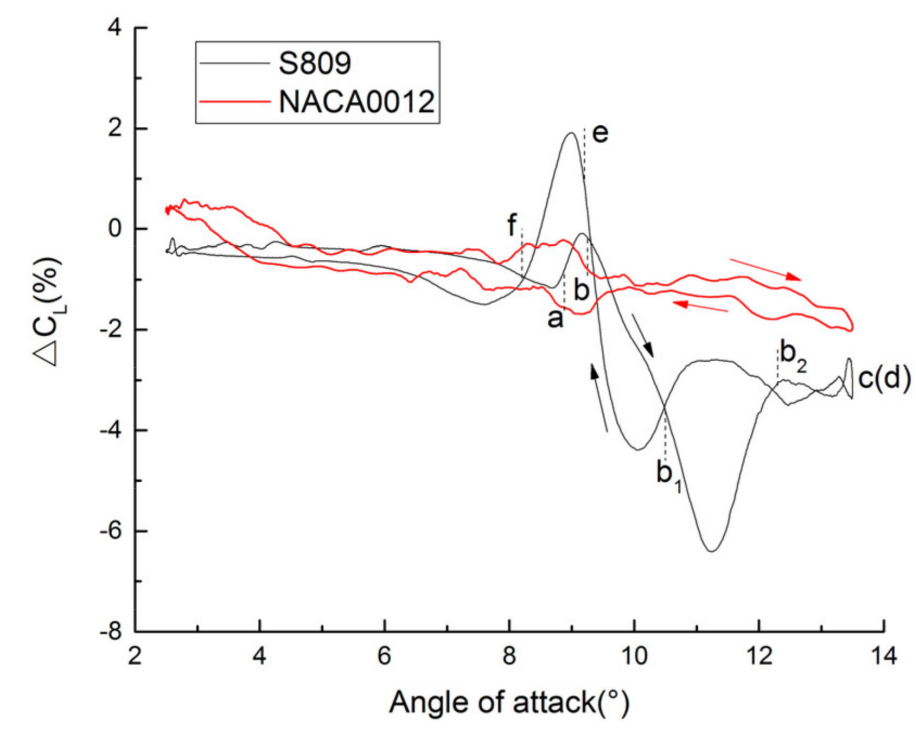

Figure 7. Relative increment loops of two airfoils after loading particles with a concentration of $1 \%$.

In Figures 8 and 9, for Case 2, particles also have little effect on the loop of NACA0012 airfoil. The angle of attack, where the maximum lift coefficient is obtained, is unchanged, which is different from that of S809 airfoil. During the up stroke, the relative increments of two airfoils are around $-0.25 \%$, except in the last section. From $12.5^{\circ}$ to $13.5^{\circ}$, they increase to $-1.3 \%$ and $-6.85 \%$, respectively. During the down stroke, the relative increment of NACA0012 airfoil continuously increases and obtains the maximum value of $-2.47 \%$ at the angle of attack of $7.5^{\circ}$. Then, it keeps a slow decrease until the end. The relative increment of S809 airfoil rapidly decreases first and obtains the value of $-3.5 \%$ at the angle of attack of about $12^{\circ}$. In the middle section, a fluctuation is shown, and the cause is revealed above. From $6.5^{\circ}$ to $2.5^{\circ}$, the relative increment keeps decreasing. Obviously, areas bounded by the two relative increment loops; in Case 2, it is larger than those in Case 1, which illustrates the grater difference of the former between up and down strokes. 


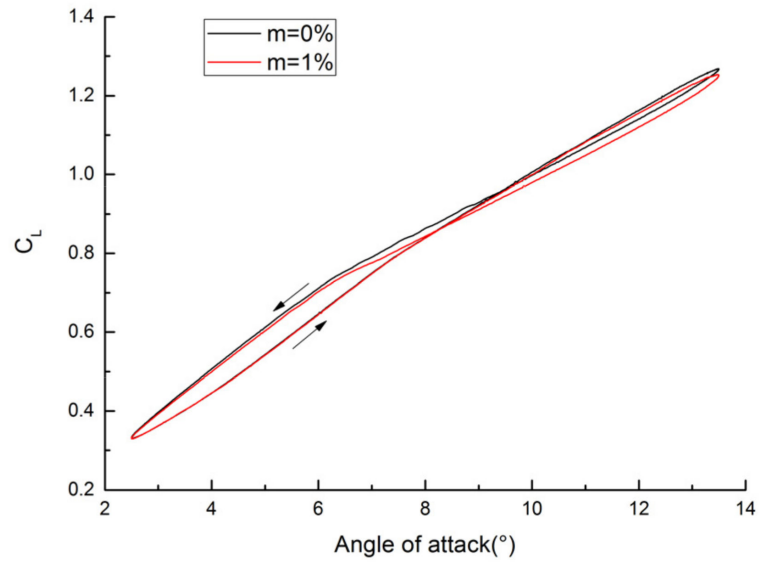

(a)

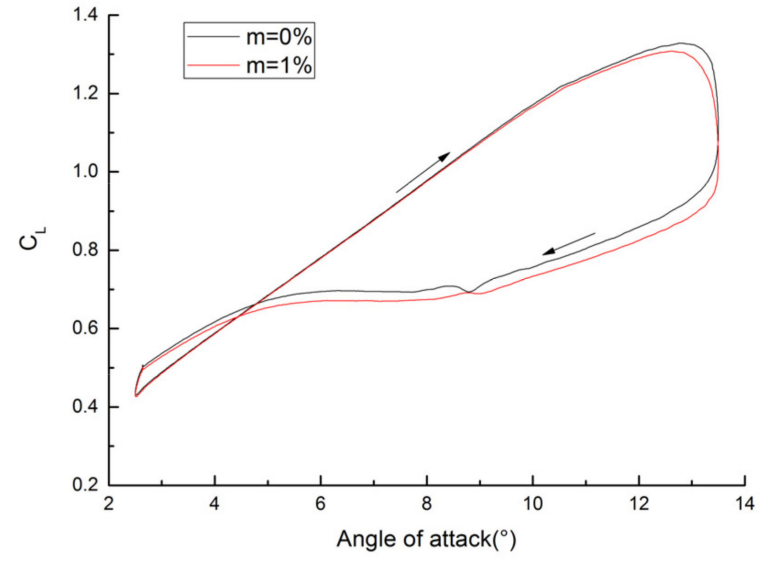

(b)

Figure 8. Lift coefficient hysteresis loops of two airfoils for Case 2: (a) NACA0012 airfoil; (b) S809 airfoil.

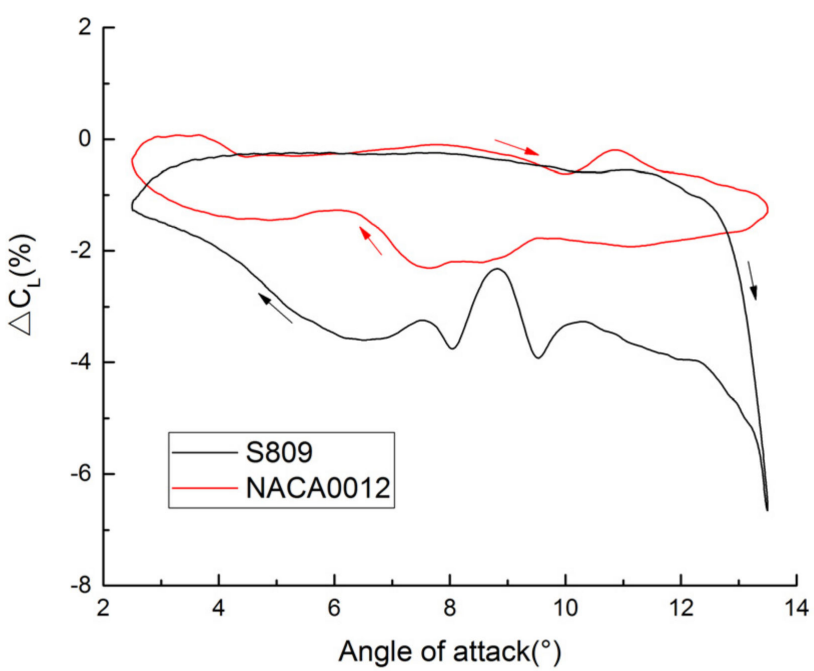

Figure 9. Relative increment loops of two airfoils after loading particles with a concentration of $1 \%$.

In Figures 10 and 11, for Case 3, during the up stroke, relative increments of two airfoils are both smaller than 1\% in most sections, except for that of S809 airfoil at angles of attack smaller than $4^{\circ}$. A maximum value of $-3.02 \%$ is obtained at the minimum angle of attack. During the down stroke, the increment of NACA0012 airfoil has a mean value of $-1.9 \%$, and the maximum value of $-2.32 \%$ is obtained at the angle of $7.6^{\circ}$. For S809 airfoil, the relative increment rapidly increases from $-1.37 \%$ at $13.5^{\circ}$ to $-6 \%$ at $12.3^{\circ}$. Then, it increases again with a small slope. The maximum value, which is about $-7 \%$, appears at a middle angle of attack. In addition, areas bounded by the relative increment loops of two airfoils further increases, and it is greatly obvious for S809 airfoil. Therefore, a larger reduced frequency can increase the range of the large aerodynamic performance loss and the difference between two airfoils, especially during the down stroke. 


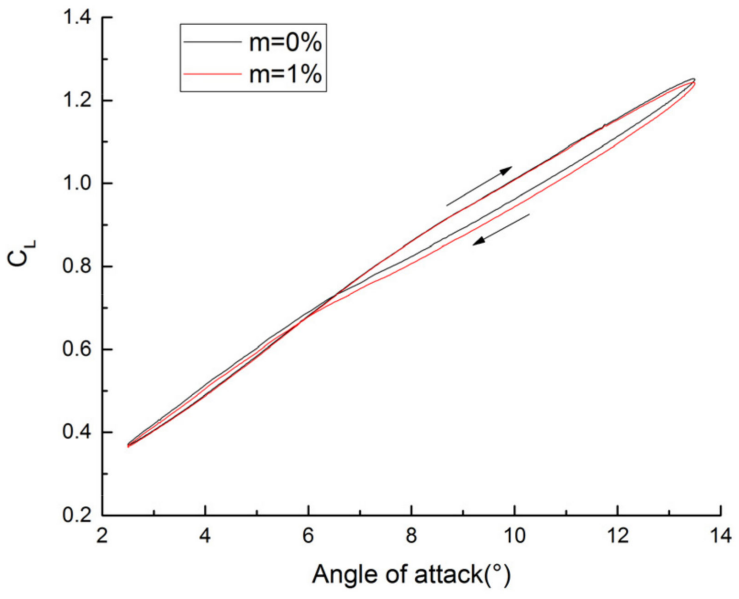

(a)

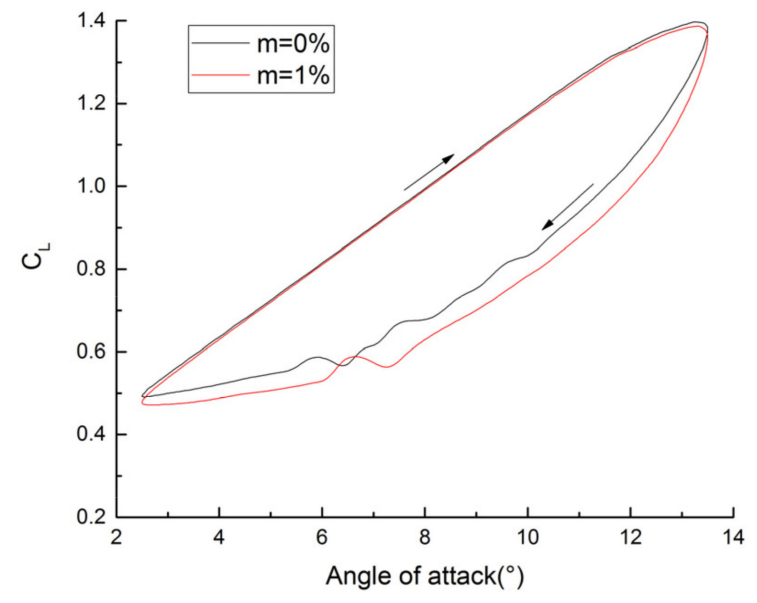

(b)

Figure 10. Lift coefficient hysteresis loops of two airfoils for Case 3: (a) NACA0012 airfoil; (b) S809 airfoil.

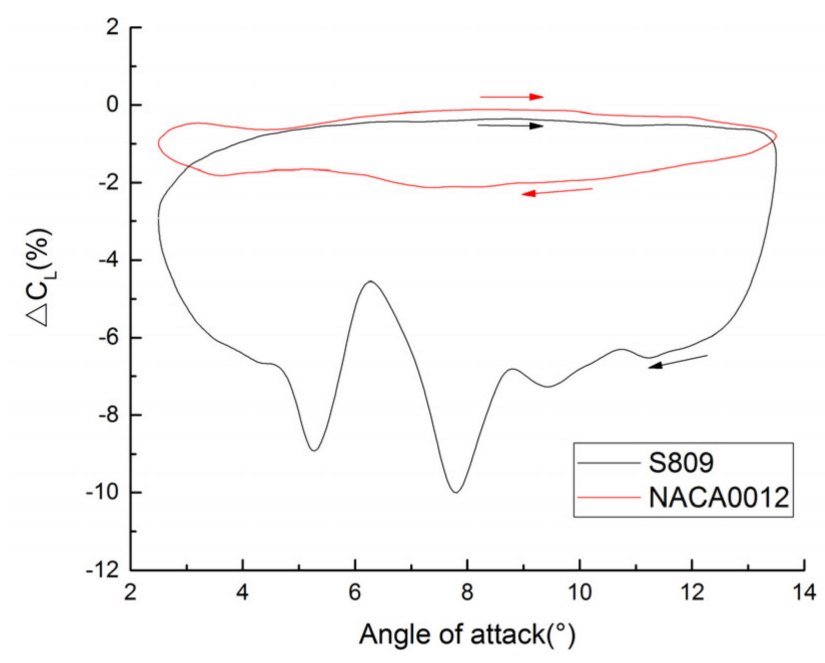

Figure 11. Relative increment loops of two airfoils after loading particles with a concentration of $1 \%$.

\subsection{Hysteresis Loops at Different Mean Angles of Attack}

In the previous section, the comparison is presented at a mean angle of attack of $8^{\circ}$. Another two mean angles of attack are adopted to further reveal their difference. The default particle mass concentration is also $1 \%$ and the more details are listed in Table 3. Then, the computed results of these three cases are discussed, respectively.

Table 3. The pitching parameters of three cases.

\begin{tabular}{|c|c|c|c|c|c|c|}
\hline Case Number & Stokes Number (St) & $\operatorname{Re} \times 10^{6}$ & $\alpha_{m}\left({ }^{\circ}\right)$ & $\alpha_{A}\left({ }^{\circ}\right)$ & $f(\mathrm{~Hz})$ & $\omega_{\text {red }}$ \\
\hline Case 4 & \multirow{3}{*}{0.053} & \multirow{3}{*}{1.01} & 4 & \multirow{3}{*}{5.5} & 1.85 & 0.0770 \\
\hline Case 2 & & & 8 & & 1.85 & 0.0770 \\
\hline Case 5 & & & 11 & & 1.85 & 0.0770 \\
\hline
\end{tabular}

In Figure 12a, for Case 4, the loop of NACA0012 airfoil is hardly changed by particles, due to its insensitivity during both up and down strokes. However, in Figure 12b, the loops of S809 airfoil during the beginning of the down stroke have apparently smaller lift coefficients than those during the end of the up stroke, which is caused by the light stall. Although particles have an obvious change in this region, it is still too small to be paid 
attention to. Therefore, the effect of particles on the lift coefficient is slight and negligible at the default particle mass concentration in the whole loop.

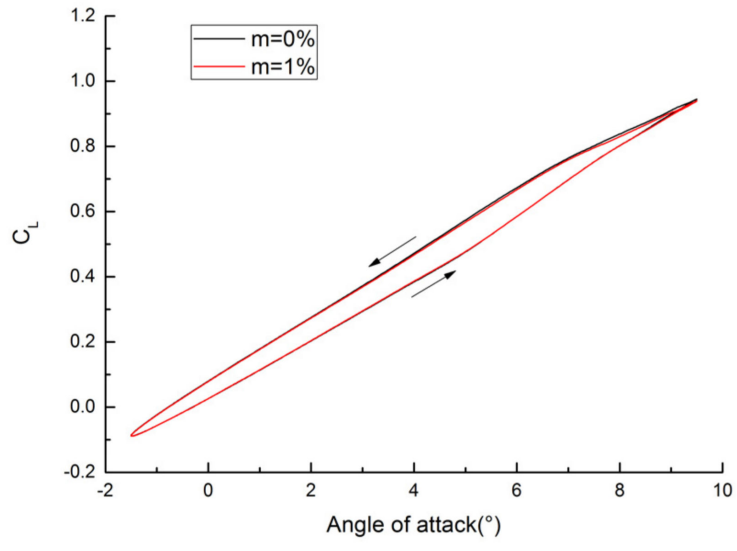

(a)

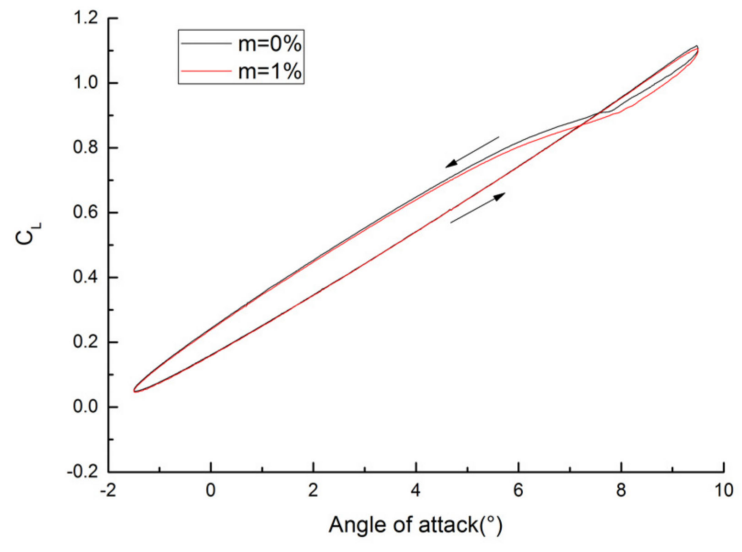

(b)

Figure 12. Hysteresis loops of two airfoils for Case 4: (a) NACA0012 airfoil; (b) S809 airfoil.

For two airfoils, the angle of attack, at which the maximum lift coefficient is obtained, is unchanged by particles. In order to ascertain this phenomenon, two larger particle mass concentrations of $3 \%$ and $5 \%$ are adopted, and the results are listed in Table 4 . It is found that particles do not change the angle at which the maximum lift coefficient is obtained, even though it is under the effect of light stall at moderate and high reduced frequencies.

Table 4. Angles of attack, at which the maximum lift coefficient is obtained, for Case 4.

\begin{tabular}{|c|c|c|}
\hline \multirow{2}{*}{ Particle Mass Concentration } & \multicolumn{2}{|c|}{ Maximum Lift Coefficient Angle $\left({ }^{\circ}\right)$} \\
\hline & NACA0012 & S809 \\
\hline $0 \%$ & \multirow{4}{*}{9.5} & \multirow{4}{*}{9.5} \\
\hline $1 \%$ & & \\
\hline $3 \%$ & & \\
\hline $5 \%$ & & \\
\hline
\end{tabular}

The comparison for Case 2 was presented in Figures 8 and 9. In Table 5, for NACA0012 airfoil, all angles of attack, at which the maximum lift coefficient is obtained, were $13.5^{\circ}$, while for S809 airfoil, the value decreases with the mass concentration. This may illustrate that the angle of attack, at which the maximum lift coefficient angle is obtained, can be changed by particles in the region, which suffers the effect of deep stall.

Table 5. Angles of attack, at which the maximum lift coefficient is obtained, for Case 2.

\begin{tabular}{|c|c|c|}
\hline \multirow{2}{*}{ Particle Mass Concentration } & \multicolumn{2}{|c|}{ Maximum Lift Coefficient Angle ( ${ }^{\circ}$ ) } \\
\hline & NACA0012 & S809 \\
\hline $0 \%$ & \multirow{4}{*}{13.5} & 12.8 \\
\hline $1 \%$ & & 12.6 \\
\hline $3 \%$ & & 12.3 \\
\hline $5 \%$ & & 12 \\
\hline
\end{tabular}

Finally, as shown in Figure 13 for Case 5, two airfoils both suffer the effect of deep stall and have different degradations of the lift coefficient near the maximum angle of attack. In 
Figure 14, during the up stroke, the relative increment of NACA0012 airfoil is smaller than $-1.25 \%$ at angles of attack less than $15^{\circ}$ and increases to $-3.01 \%$ at $16.5^{\circ}$. With the angle of attack decreasing, it increases again at a greater speed rate. Then, the maximum increment of $-7.02 \%$ is obtained at $13.9^{\circ}$. In the following region, the relative increment linearly decreases until the angle of attack reaches to $6.2^{\circ}$. For 5809 airfoil, the relative increment is smaller than $-1.5 \%$ at angles of attack less than $12^{\circ}$ and rapidly increases at following angles of attack. The first peak value of $-7.23 \%$ appears at $15.2^{\circ}$ and it decreases to $-3 \%$ at $16.5^{\circ}$. During the down stroke, the relative increment increases again, and the second peak value is $-7.05 \%$ at $9.5^{\circ}$. Then, the decrease runs through the rest region. In brief, particles have large effect on the lift coefficient of both airfoils during the down stroke. However, during the second half of the up stroke, particles also have a large effect on the lift coefficient of S809 airfoil.

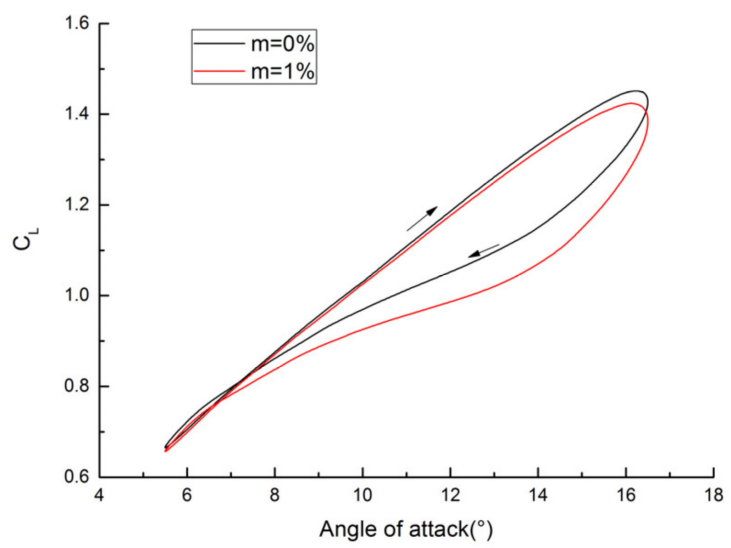

(a)

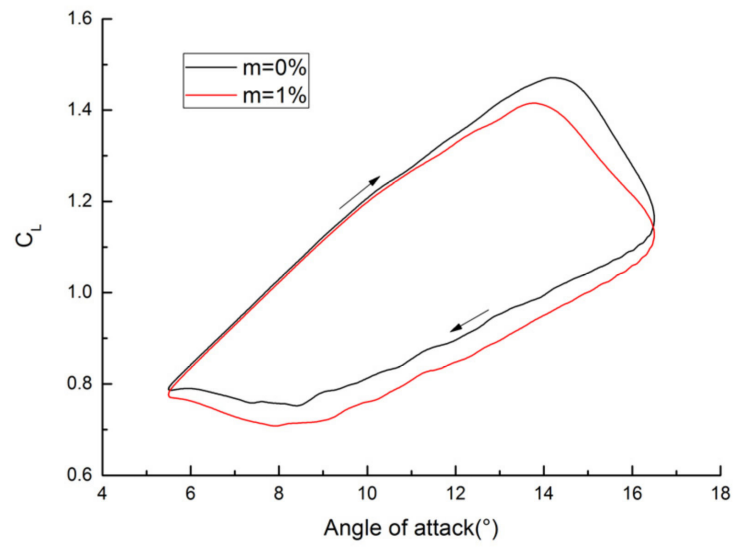

(b)

Figure 13. Hysteresis loops of two airfoils for Case 5: (a) NACA0012 airfoil; (b) S809 airfoil.

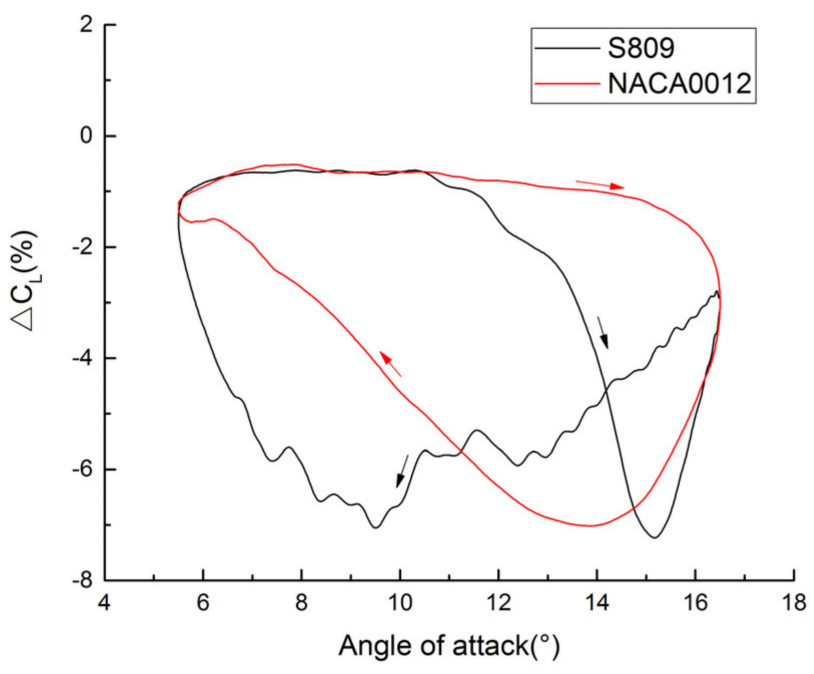

Figure 14. Relative increment loops of two airfoils after loading particles with a concentration of $1 \%$.

Table 6 shows angles of attack, at which the maximum lift coefficient is obtained, of two airfoils at different particle concentrations. They both decrease with the particle mass concentration. In summary, particles can change the angle of attack, at which the maximum lift coefficient is obtained, in the region under the effect of deep stall. 
Table 6. Angles of attack, at which the maximum lift coefficient is obtained, for Case 5.

\begin{tabular}{ccc}
\hline \multirow{2}{*}{ Particle Mass Concentration } & \multicolumn{2}{c}{ Maximum Lift Coefficient Angle ( ${ }^{\circ}$ ) } \\
\cline { 2 - 3 } & NACA0012 & S809 \\
\hline $0 \%$ & 16.2 & 14.3 \\
\hline $1 \%$ & 16 & 13.6 \\
\hline $3 \%$ & 15.8 & 13 \\
\hline $5 \%$ & 15.5 & 12.4 \\
\hline
\end{tabular}

\section{Conclusions}

This paper shows the comparison of relative increment loops of the lift coefficient caused by particles between an aircraft airfoil (NACA0012) and a wind turbine airfoil (S809) at different reduced frequencies. Then, the differences of relative increment loops of the lift coefficient between two airfoils at three mean angles of attack are also discussed. Three important conclusions can be reached as follows:

(1) The reduced frequency has little effect on the value of the maximum increment of the lift coefficient caused by particles, but a larger one can enhance the hysteresis effect and change the angle of attack, at which the maximum increment is obtained, from the up stroke to the down stroke. The increment of the lift coefficient and its difference between two airfoils at a larger reduced frequency are smaller and larger during up and down strokes, respectively.

(2) Compared to that of NACA0012 airfoil, the relative increments of S809 airfoil are obviously greater at three mean angles of attack, especially at $8^{\circ}$, which is the commonly used operating angle.

(3) The angle of attack, at which the maximum lift coefficient is obtained, can be significantly changed by particles in two regions: one is under the effect of deep stall, the other is under the effect of light deep at a low reduced frequency.

Author Contributions: Conceptualization, J.J. and Z.L.; data curation, D.Z.; methodology, J.J., Z.L. and T.G.; project administration, Z.L.; software, J.J.; validation, J.J., Z.L., D.Z. and Q.L.; writingoriginal draft preparation, J.J.; writing-review and editing, D.Z. and Q.L.; visualization, J.J.; supervision, Z.L. All authors have read and agreed to the published version of the manuscript.

Funding: This work was supported by the National Natural Science Foundation of China (Grant No. 11872212), the National Science Foundation of Jiangsu Province (Grant No. BK20190386), and a project funded by the Priority Academic Program Development of Jiangsu Higher Education Institutions.

Institutional Review Board Statement: Not applicable.

Informed Consent Statement: Not applicable.

Data Availability Statement: The data presented in this study are available on request from the corresponding author.

Conflicts of Interest: The authors declare no conflict of interest.

\section{References}

1. Ham, N.D.; Young, M.I. Torsional Oscillation of Helicopter Blades Due to Stall. J. Aircr. 1966, 3, 218-224. [CrossRef]

2. Madden, P.A. Angle-of Attack Distribution of a High-Speed Helicopter Rotor. J. Am. Helicopter Soc. 1967, 12, 41-49. [CrossRef]

3. Carta, F.O. An Analysis of the Stall Flutter Instability of Helicopter Rotor Blades. J. Am. Helicopter Soc. 1967, 12, 1-18. [CrossRef]

4. Ham, N.D. Stall Flutter of Helicopter Rotor Blades: A Special Case of the Dynamic Stall Phenomenon. J. Am. Helicopter Soc. 1967, 12, 19-21. [CrossRef]

5. Ham, N.D.; Garelick, M.S. Dynamic Stall Considerations in Helicopter Rotors. J. Am. Helicopter Soc. 1968, 13, 49-55. [CrossRef]

6. McCroskey, W.; Carr, L.; McAlister, K. Dynamic Stall Experiments on Oscillating Airfoils. AIAA J. 1976, 14, 57-63. [CrossRef]

7. Mcalister, K.W.; Pucci, S.L.; Mccroskey, W.J.; Carr, L.W. An Experimental Study of Dynamic Stall on Advanced Airfoil Section. Volume 2: Pressure and Force Data. NASA Tech. Memo. 1982, 84245, 1-639.

8. Leishman, J.G.; Beddoes, T.S. A Semi-Empirical Model for Dynamic Stall. J. Am. Helicopter Soc. 1989, 34, 3-17. 
9. Tuncer, I.H.; Wu, J.C.; Wang, C.M. Theoretical and Numerical Studies of Oscillating Airfoils. AIAA J. 1990, $28,1615-1624$. [CrossRef]

10. Raffel, M.; Kompenhans, J.; Wernert, P. Investigation of the Unsteady Flow Velocity Field above an Airfoil Pitching under Deep Dynamic Stall Conditions. Exp. Fluids 1995, 19, 103-111. [CrossRef]

11. Wernert, P.; Geiler, W.; Raffel, M.; Kompenhans, J. Experimental and Numerical Investigations of Dynamic Stall on a Pitching NACA 0012 Airfoil. AIAA J. 1996, 34, 982-989. [CrossRef]

12. Spentzos, A.; Barakos, G.; Badcock, K.; Richards, B.; Wernert, P.; Schreck, S.; Raffel, M. Investigation of Three-Dimensional Dynamic Stall Using Computational Fluid Dynamics. AIAA J. 2005, 43, 1023-1033. [CrossRef]

13. Liu, J.; Luo, K.; Sun, H.; Huang, Y.; Liu, Z.; Xiao, Z. Dynamic Response of Vortex Breakdown Flows to a Pitching Double-Delta Wing. Aerosp. Sci. Technol. 2018, 72, 564-577. [CrossRef]

14. Liu, J.; Chen, J.; Ren, H.; Zhang, Y.; He, X.; Xiao, Z. Correlations of Unsteady Vortex Burst Point and Dynamic Stability over a Pitching Double-delta Wing. Aerosp. Sci. Technol. 2020, 107, 106256. [CrossRef]

15. Yi, Y.; Hu, T.; Liu, P.; Qu, Q.; Eitelberg, G.; Akkermans, R.A. Dynamic Lift Characteristics of Nonslender Delta Wing in Large-amplitude-pitching. Aerosp. Sci. Technol. 2020, 105, 105937. [CrossRef]

16. Hu, T.; Zhao, Y.; Liu, P.; Qu, Q.; Guo, H.; Akkermans, R.A. Investigation on Lift Characteristics of a Double-delta Wing Pitching in Various Reduced Frequencies. Proc. Inst. Mech. Eng. Part. G J. Aerosp. Eng. 2021. [CrossRef]

17. Butterfield, C.P.; Simms, D.; Scott, G.; Hansen, A.C. Dynamic Stall on Wind Turbine Blades. In Proceedings of the American Wind Energy Association Conference: Windpower ‘91, Palm Springs, CA, USA, 1 December 1991; pp. $24-27$.

18. Shipley, D.E.; Miller, M.S.; Robinson, M.C. Dynamic Stall Occurrence on a Horizontal Axis Wind Turbine Blade; Office of Scientific \& Technical Information Technical Reports; National Renewable Energy Laboratory: Golden, CO, USA, 1995.

19. Ramsay, R.F.; Hoffman, M.J.; Gregorek, G.M. Effects of Grit Roughness and Pitch Oscillations on the S809 Airfoil; Office of Scientific \& Technical Information Technical Reports; National Renewable Energy Laboratory: Golden, CO, USA, 1995.

20. Ekaterinaris, J.A.; Platzer, M.F. Computational Prediction of Airfoil Dynamic Stall. Prog. Aerosp. Sci. 1998, 33, 759-846. [CrossRef]

21. Larsen, J.W.; Nielsen, S.R.K.; Krenk, S. Dynamic Stall Model for Wind Turbine Airfoils. J. Fluids Struct. 2007, 23, 959-982. [CrossRef]

22. Sheng, W.; Galbraith, R.A.; Coton, F.N. A Modified Dynamic Stall Model for Low Mach Numbers. J. Sol. Energy Eng. 2007, $130,653$.

23. Pruski, B.J.; Bowersox, R. Leading-Edge Flow Structure of a Dynamically Pitching NACA 0012 Airfoil. Aiaa J. 2013, 51, $1042-1053$. [CrossRef]

24. Liu, X.; Liang, S.; Li, G.; Godbole, A.; Lu, C. An Improved Dynamic Stall Model and Its Effect on Wind Turbine Fatigue Load Prediction. Renew. Energy 2020, 156, 117-130. [CrossRef]

25. Martinat, G.; Hoarau, Y.; Braza, M.; Vos, J.; Harran, G. Numerical Simulation of the Dynamic Stall of a NACA 0012 Airfoil Using DES and Advanced OES/URANS modelling. In Advances in Hybrid RANS-LES Modelling; Springer: Berlin/Heidelberg, Germany, 2008; Volume 97, pp. 271-278.

26. Martinat, G.; Braza, M.; Hoarau, Y.; Harran, G. Turbulence Modelling of the Flow Past a Pitching NACA0012 Airfoil at Formula Not Shown and Formula Not Shown Reynolds Numbers. J. Fluids Struct. 2008, 24, 1294-1303. [CrossRef]

27. Guntur, S.; Schreck, S.; Sorensen, N.N.; Schreck, S.; Bergami, L. Modeling Dynamic Stall on Wind Turbine Blades Under Rotationally Augmented Flow Fields; Technical Report; National Renewable Energy Laboratory: Golden, CO, USA, 2015.

28. Zhu, C.; Wang, T.; Zhong, W. Combined Effect of Rotational Augmentation and Dynamic Stall on a Horizontal Axis Wind Turbine. Energies 2019, 12, 1434. [CrossRef]

29. Li, G.; Zhang, W.; Jiang, Y.; Pengyu, Y. Experimental Investigation of Dynamic Stall Flow Control for Wind Turbine Airfoils Using a Plasma Actuator. Energy 2019, 185, 90-101.

30. Li, G.; Yi, S. Large Eddy Simulation of Dynamic Stall Flow Control for Wind Turbine Airfoil Using Plasma Actuator. Energy 2020, $212,118753$.

31. Zhu, C.; Chen, J.; Wu, J.; Wang, T. Dynamic Stall Control of the Wind Turbine Airfoil via Single-row and Double-row Passive Vortex Generators. Energy 2019, 189, 116272. [CrossRef]

32. Zhu, C.; Qiu, Y.; Wang, T. Dynamic Stall of the Wind Turbine Airfoil and Blade Undergoing Pitch Oscillations: A Comparative Study. Energy 2021, 222, 120004. [CrossRef]

33. He, T. Study the Dynamic Stall Characteristics of Wind Turbine Airfoil under Sand-wind Environment; Lanzhou University of Technology: Lanzhou, China, 2017.

34. Guo, T.; Jin, J.; Lu, Z.; Zhou, D.; Wang, T. Aerodynamic Sensitivity Analysis for a Wind Turbine Airfoil in an Air-Particle Two-Phase Flow. Appl. Sci. 2019, 9, 3909. [CrossRef]

35. Menter, F.R. Two-equation Eddy-viscosity Turbulence Models for Engineering Applications. AIAA J. 1994, 32, $1598-1605$. [CrossRef]

36. Menter, F.R.; Langtry, R.B.; Likki, S.R.; Suzen, Y.B.; Huang, P.G.; Völker, S. A Correlation-Based Transition Model Using Local Variables-Part I: Model Formulation. J. Turbomach. 2006, 128, 413-422. [CrossRef]

37. Zhu, C.; Wang, T. Comparative Study of Dynamic Stall under Pitch Oscillation and Oscillating Freestream on Wind Turbine Airfoil and Blade. Appl. Sci. 2018, 8, 1242-1262. [CrossRef]

38. ANSYS Inc. FLUENT Theory Guide, Release 16.0; ANSYS Inc.: Canonsburg, PA, USA, 2015. 
39. Morsi, S.A.; Alexander, A.J. An Investigation of Particle Trajectories in Two-Phase Flow Systems. J. Fluid Mech. 1972, 55, 193-208. [CrossRef]

40. Hand, M.M.; Simms, D.A.; Fingersh, L.J.; Jager, D.W.; Cotrell, J.R.; Schreck, S.; Larwood, S.M. Unsteady Aerodynamics Experiment Phase VI: Wind Tunnel Test Configurations and Available Data Campaigns; National Renewable Energy Laboratory: Golden, CO, USA, 2001.

41. Somers, D.M. Design and Experimental Results for the S809 Airfoil; National Renewable Energy Laboratory: Golden, CO, USA, 1997; pp. 1-97.

42. Luo, K.; Chen, S.; Cai, D.Y.; Fan, J.R.; Cen, K.F. Experimental Study of Flow Characteristics in the Near Field of Gas-Solid Two-Phase Circular Cylinder Wakes. Proc. Chin. Soc. Electr. Eng. 2006, 26, 116-120. 